\title{
MICROBIAL QUALITY OF MILK AVAILABLE IN KATHMANDU VALLEY
}

\author{
Arjyal C, Dahal B N*, Khadka B*
}

\section{ABSTRACT}

With an objective to find microbial quality of the market milk available in Kathmandu valley, this study was conducted in the Microbiology Laboratory, Himalayan College of Agriculture Science and Technology (HICAST). Different milk brands were collected from different outlets in the valley and analyzed for microbial quality. The samples were cultured using the standard microbiological techniques. Almost all the samples showed the presence of bacterial growth including coliform bacteria. The bacterial isolates were of 7 different genera. E. coli was the most frequently isolated organism (92\%) followed by coagulase negative Staphylococci (CONS) (24\%). Other organisms isolated were Bacillus species, Staphylococcus aureus, Streptococcus species, Salmonella species, Shigella species. The culture results were similar to direct microscopic count results and showed that bacterial contamination in some of the samples was too numerous to be counted. Thus, it was concluded that the market milk available in Kathmandu is contaminated with various types of microorganisms and does not meet the required standard. The dairy industries should work seriously to maintain the standards of their products.

\section{Key Words: Microbiology, Contamination, Milk, Quality, Coliform.}

\section{INTRODUCTION}

Milk is one of the most complete single foods available in nature for health and promotion of growth. It supplies the body building proteins, bone-forming minerals and healthgiving vitamins and furnishes energy giving lactose and milk fat. Milk contains the above nutrients in an easily digestible and assimilable form. All of these properties make milk an important and ideal food. ${ }^{1}$

Since milk is a good medium for practically all microorganisms, there is a risk that pathogenic bacteria will develop in milk and thus spread through milk. The microorganisms often encountered in milk are of various types including spoilage bacteria like Proteus spp., Serratia spp., Pseudomonas fluorescens, Brevibacterium linens; spore forming bacteria like Bacillus spp., Clostridium spp.; coliform bacteria like Escherichia coli, Enterobacter aerogenes etc. In addition to these, many other pathogenic types like Streptococci, tubercle bacilli, Brucella abortus, Bacillus anthracis, Corynebactrium diphtheriae, Salmonella spp., Shigella spp., Staphyloccocci, Clostridium botulinum are found in milk. ${ }^{2}$

Human infections may be caused by the ingestion of animal milk which contains microorganisms derived either from the animal, e.g. by contamination with its feces, or from the environment or from milk handlers such as dairy workers. ${ }^{3}$ The diseases transmitted by milk include tuberculosis, typhoid fever, scarlet fever, septic sore throat, undulant fever, gastroenteritis, diphtheria. ${ }^{4}$ Other diseases include dysentery, food poisoning, anthrax and paratyphoid fever. ${ }^{2}$

The annual bulletin (2001/2002) published by Department of Food Technology and Quality Control has shown that the milk available in Kathmandu valley is highly contaminated by coliform and other group of microorganisms. ${ }^{5}$

* Integrated Bioscientific Research Group (BIOINT), Kupondol, Lalitpur, Nepal.

** Himalayan College of Agriculture Science and Technology (HICAST), Gatthaghar, Bhaktapur, Nepal.

Address for correspondence : Charu Arjyal

Integrated Bioscientific Research Group (BIOINT), Kupondol, Lalitpur, Nepal.

Email: charuarjyal@hotmail.com 
This trend has been persisting since many years and there seems to be no improvement in the quality of the milk. This study was undertaken with a view to find out the microbial quality and also the microbial load of the major milk brands available in Kathmandu valley. It was felt necessary that everybody involved with milk and dairy products should be familiar with the nature and characteristics of pathogenic bacteria so that they can take the appropriate measures to combat them in the daily production and use.

\section{MATERIALS AND METHODS}

A total of 14 different milk brands $(A, B, C \ldots, N)$ available at the major outlets in Kathmandu valley were analyzed to determine the microbial load and the quality of the milk. For each brand, 10 samples were analyzed for the reliability of the test.

The study was carried out following the standard microbiological technique as listed below. After collection of the sample, they were transported to the laboratory within a period of 30 minutes to 1 hour and processed immediately. The microbiological analysis included three major tasks Direct Microscopic Count (DMC), Dye Reduction Test and Total Plate Count (TPC).

DMC was performed by the conventional Breed count method and the total number of organisms per ml of milk was determined. Dye reduction test was performed by Methylene Blue Reduction Time (MBRT) test. The time required for the reduction of methylene blue, a redox dye, by the milk sample was determined. The quality of the milk was then interpreted using the standard chart. ${ }^{6}$

Total Plate Count was performed following the pour plate method. The total microbial load was found using the all purpose nutrient agar (NA) and the total coliform count per $\mathrm{ml}$ of the sample using the selective media for coliforms, Violet Red Bile Agar (VRBA).

The different types of colonies on these two agar media were then sub-cultured to obtain pure culture of these organisms. The pure culture thus obtained was used for different biochemical tests and the identification of the bacteria was done according to their colonial, morphological and biochemical characteristics.

\section{RESULT AND DISCUSSION}

The result of direct microscopic count (DMC) showed that the sample $\mathrm{N}$ had the minimum bacterial load i.e. 3961

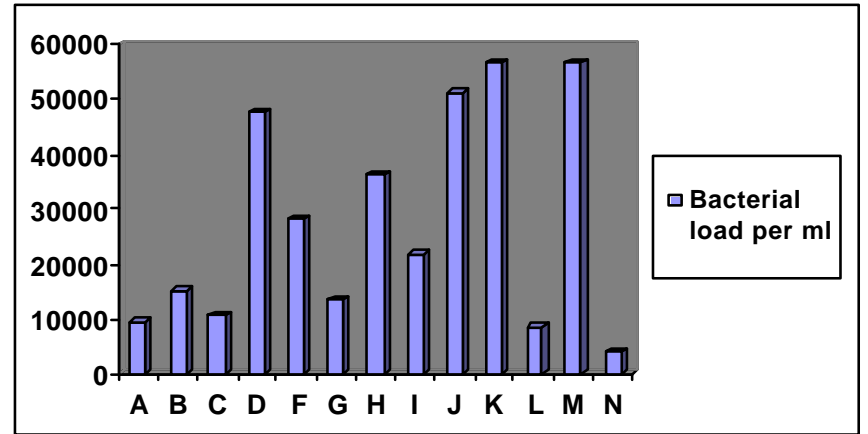

Fig. 1 : Bacterial load per milliliter in milk by direct microscopic count (DMC) method bacteria per ml milk

whereas the maximum load was found in sample $\mathrm{E}$ in which the number of bacteria was too numerous to be counted (TNTC) and could not be shown in the figure. Among the countable ones, sample $\mathrm{K}$ and $\mathrm{M}$ had maximum load i.e. 56593 bacteria per $\mathrm{ml}$ milk. The results are expressed in figure 1 .

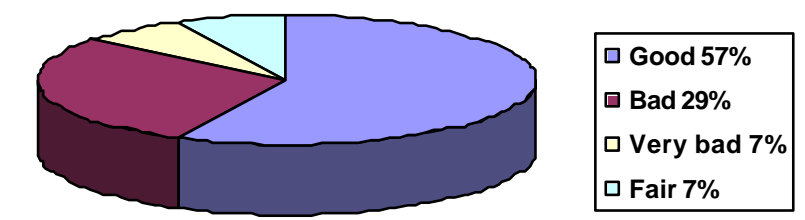

Fig. 2 : Quality of milk samples as shown by methylene blue reduction time (MBRT) test

The results of methylene blue reduction time (MBRT) test as shown in figure 2 showed that eight of the samples were of good quality, one of fair, four of bad quality and one of very bad quality. The result of this test is based on the approximate estimation of the quality of the milk using a standard value chart. ${ }^{6}$

Methylene Blue Reduction time test like other dye reduction tests is usually done in dairy industry for assessing the overall microbial quality of raw milk. ${ }^{7}$ This study was carried out in pasteurized milk but the failure of the milk samples to show good results raises the question whether pasteurization was carried out or not.

The total plate count (TPC) results as shown in table I showed that none of the samples was free of bacterial contamination. Except one, all the samples showed the presence of coliforms. The total microbial count per ml milk was very high and in some of the samples, it was too numerous to be counted (TNTC).

The result shown by direct microscopic count method (Figure 1) and by total count method (Table I) does not match exactly. It 
Table I : Average number of bacteria and coliform in the milk samples per $\mathrm{ml}$

\begin{tabular}{c|c|c}
\hline Sample & Average number of bacteria per $\mathbf{m l}$ & Average number of coliform per $\mathbf{m l}$ \\
A & 30000 & 1000 \\
B & 75000 & 4000 \\
\hline C & 18000 & 300 \\
D & 40000 & TNTC \\
E & 20000 & 6400 \\
\hline F & 13000 & 1000 \\
G & 400 & 100 \\
\hline H & 185 & 30 \\
\hline I & 6300 & 5800 \\
\hline J & TNTC & TNTC \\
\hline K & TNTC & TNTC \\
\hline L & 80000 & 9233 \\
\hline M & TNTC & 5883 \\
\hline N & 800 & 0
\end{tabular}

TNTC-Too Numerous To Be Counted

may be because of the following reasons. The microscopic method has some drawbacks - both viable and non viable cells are enumerated, microbial cells are not uniformly distributed relative to single cells or clumps; some cells do not take the stain well and may not be counted.? The pour plate method also has some disadvantages as some of the organisms may be trapped beneath the surface of the medium when it gels, and the organism which are not able to withstand temporary exposure to the temperature of the liquid agar medium can not be isolated. ${ }^{8}$

Whatever may be the drawbacks, the presence of high microbial load in milk samples cannot be ignored.

The annual bulletin (2001/2002) published by Department of Food Technology and Quality Control also reports that out of 165 samples of pasteurized milk analyzed, $150(91 \%)$ samples were highly contaminated with coliforms. ${ }^{5}$

A large number of bacteria present in milk indicate poor hygiene and negligence of the suppliers. Proper heat treatment is sufficient to destroy the coliform bacteria, and its presence in pasteurized milk serves as an index of recontamination or post pasteurization contamination, largely due to poor hygienic practices. ${ }^{9}$ The main focus was done to detect the presence of coliforms not because coliform bacteria are more dangerous than other saprophytic bacteria, but they are used as indicator bacteria of any contamination of the pasteurized milk.

In raw milk, the number of coliforms is a measure of hygiene exercised in milking and treatment of the milk. The tests for coliforms reveal whether post-pasteurization contamination has taken place or not, since all coliforms are killed by HTST (high temperature short time) pasteurization. ${ }^{2}$

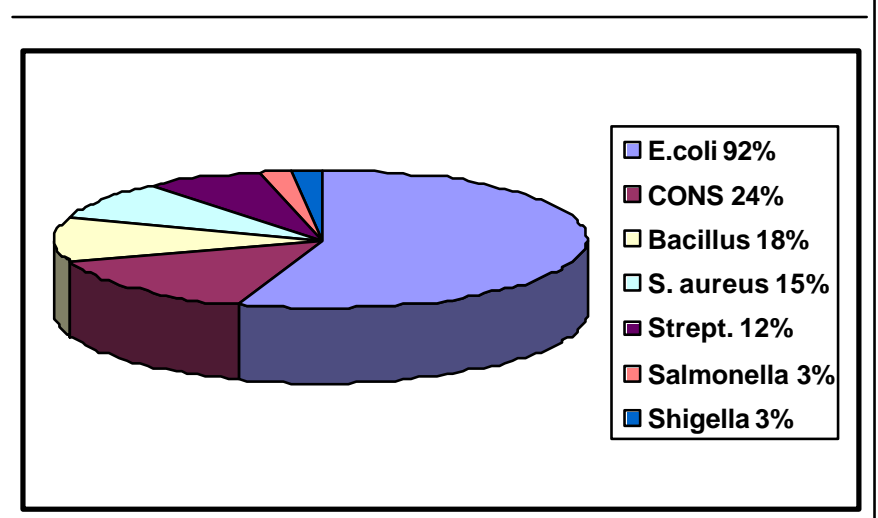

Figure 3 : Different bacterial types isolated from the milk samples

Out of the 14 milk samples, $92 \%, 24 \%, 18 \%, 15 \%, 12 \%, 3 \%$, $3 \%$ samples were found to be positive for E.coli, coagulase negative staphylococci (CONS), Bacillus spp., Staphylococcus aureus, Streptococcus spp., Salmonella spp., Shigella spp., respectively (figure 3 ).

In a survey of raw milk, it was found that out of the 129 samples, $25 \%, 37.2 \%, 5.4 \%, 7.7 \%, 18.6 \%, 1.6 \%$, were positive for E.coli, Salmonella spp., Shigella spp., Klebsiella sp., Citrobacter spp., Pseudomonas spp. respectively. ${ }^{10}$ The types of bacteria found in these studies is similar but the incidence of microbial contamination of milk in our study is found to be very high which is not a good indication.

As tabulated in table II, most of the milk samples showed the presence of multiple isolates and none of the milk samples are free from bacterial contamination.

It was found that the milk supplied by various dairies in Kathmandu valley is not free from microorganisms. Among 
Table II : Types of bacteria isolated from milk samples

\begin{tabular}{cl}
\hline Sample & \multicolumn{1}{c}{ Types of bacteria } \\
\hline A & CONS, E.coli \\
B & CONS, E.coli, Shigella spp. \\
\hline C & Bacillus spp., E.coli, Staphylococcus aureus \\
\hline D & E.coli, Staphylococcus aureus \\
E & E. coli, Staphylococcus aureus, Streptococcus spp. \\
\hline F & CONS, Bacillus spp., E.coli \\
\hline G & CONS, Bacillus spp., E.coli \\
H & E. coli \\
I & CONS, Bacillus spp., E.coli \\
\hline J & CONS, E.coli, Streptococcus spp. \\
\hline K & E.coli, Staphylococcus aureus, Streptococcus $\mathrm{spp}$. \\
L & Streptococcus spp., Salmonella spp., E.coli \\
\hline M & CONS, E.coli, Bacillus spp. \\
\hline N & CONS, Staphylococcus spp., Bacillus spp.
\end{tabular}

the 14 brands of milk samples analyzed, 13 showed the presence of coliforms which is an indication that the milk is contaminated from human or animal fecal matter. The presence of coliforms even in the pasteurized milk samples indicates either inadequate pasteurization process or contamination afterwards. The presence of microorganisms other than coliforms is equally dangerous and cannot be undermined. Almost all of the isolated bacteria are potential sources of different diseases.

The presence of such microorganisms in milk makes it hazardous to the health of the public and it also decreases the self-life of the milk. If the milk produced by a dairy is contaminated, undoubtedly, all other milk products are also contaminated. Moreover, the quality of the milk does not meet the standard set up by the Food Act/Regulation (HMG).

The pasteurization of milk should be done following the standard method and appropriate measures should be taken to reduce post pasteurization contamination. The sterile conditions of the dairy plant should be maintained at each and every step up to packaging to reduce the present problem of milk contamination. Our traditional practice of consuming milk only after proper boiling is an advantage to us from protecting against any diseases which may be transmitted through milk. But, the public should feel free to consume the 'pasteurized' milk even without boiling and the persisting trend of milk being contaminated with microorganisms must be improved.

\section{ACKNOWLEDGEMENT}

We are thankful to HICAST for providing the necessary laboratory facilities. We are also grateful to the members of BIOINT and the staffs of HICAST for their help.

\section{REFERENCES}

1. De. S., Market milk, out lines of Dairy Technology, Oxford University Press, Delhi. 1982, 1-89.

2 Jensen, P.S., Vorup, R., Pathogenic Bacteria, Microbiology, Danish Turnkey Dairies Ltd., 1989, 85.

3. Collee, J.E., Fraser A.G., Marmion B.P., Simmons A. (eds) Examination of water, milk, food and air In Mackie \& MoCartney, Practical Medical Microbiology, Fourteenth Edition, 1996, 892.

4. Manay, N.S., Shadaksharaswamy, M., Foods Facts and Principles, 1987, Wiley eastern Limited, New Delhi.

5. Annual Bulletin, Analysis reports on milk and milk products, In: Joshi U, Karmacharya S, Manandhar BL eds. His Majesty's Government of Nepal, Ministry of Agriculture and Cooperatives, Department of Food Technology \& Quality Control, 2001/2002, 30-42.

6. K.C., J.B., Rai. B.K. Enumeration of microorganisms in food and other samples. In Experiments in Basic Food Microbiology, Ekta Book Distributors, first Edition. 2000, 65-66.

7. Jay, J.M., Culture, Microscopic, and Sampling Methods; Determining Microorganisms and/or Their Products in Food In Modern food Microbiology, Fourth Edition, 1996, 106.

8. Pelczar, M.J., Chan, E.C.S., Krieg, N.R., Pure Cultures and Cultural Characteristics In Microbiology, Fifth Edition, 1997, 138-139.

9. Bhatta, D.R., Practicals on Dairy Microbiology, Food Microbiology Theory and Practicals, 1995, 88.

10. Regmi, S., Shah, P.K., Ranjit, D.K., Iamichhane, R., Ranjit, S., Adhikari, R.P., Prevalence of different pathogenic enteric bacteria in raw milk samples from different geographical regions of Nepal. Joumal of Nepal Public Health Association, $2001,1: 44-46$. 